Soon after his retirement he developed colonic cancer from which, after a long illness, he died on 11 January 2002. Gwyn was first and foremost a family man and he is survived by his wife Sheila (Kidd), a fellow medical student to whom he was married for 43 years. He also leaves a son, a daughter (a community paediatrician) and two grandchildren.

David Wilson

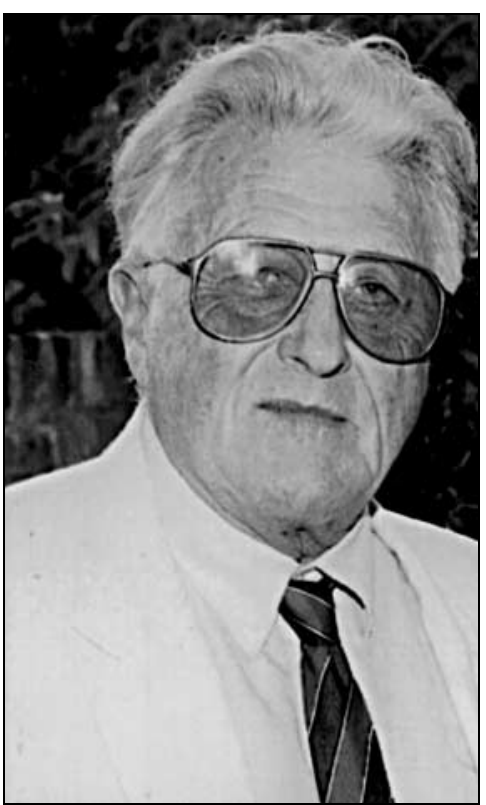

\section{Michael Gwynne Douglas} Davys

Formerly Consultant Psychiatrist, Bowden Clinic, Harrow-on-the-Hill
Dr Davys was born in 1922 in Urchfont, Wiltshire, where his father, Revd Canon S. M. D. Davys, was the vicar of St Michael's Church from 1915 to 1929. Davys was educated at Salisbury Cathedral School, then Marlborough College. In 1940, he went up to St Edmund Hall, Oxford, to read Medicine, qualifying in 1946, and continued his medical training at Guy's Hospital.

In May 1945, as one of the more senior medical students, he went to Belsen to help with the massive medical problems as concentration camps were liberated. The death rate, which had been $4 \%$ per day until 1 May, fell in 1 week to half the total and by 22 May had been reduced to 50 per day. His letter home describes 'scenes of indescribable horror, filth, squalor and disease... they have been dying of starvation and typhus at about the rate of 500-600 a day. . . I am very tired. We work a very hard 12-hour day. The scenes I have seen here will be vivid memories for the rest of my life'.

From 1950 to 1970, Davys served in the Royal Naval Volunteer Reserve, attached to HMS President. He achieved the rank of Surgeon Lieutenant Commander and was awarded the VRD, the Royal Naval Volunteer Reserve Officers' Decoration. After leaving the Navy, he returned to Guy's, qualifying as a consultant physician and psychiatrist in 1953. He remained attached to Guy's Hospital under Sir Arthur Fripp as Research Fellow in Psychiatry. He was also ward clerk and part-time resident medical officer under Dr Macdonald Critchley and Dr Meadows at the National Hospital for Nervous Diseases, Queen Square.
Upon qualifying, Davys worked mainly in the NHS as consultant psychiatrist for the East Sussex Regional Board's Child Guidance Clinic in Brighton. He had a special interest in depression in children.

In 1964, Davys left the NHS and established Bowden House, a private psychiatric clinic in Harrow-on-the-Hill, where he was Consultant Psychiatrist and Joint Medical Director until 1974. In 1966, he was elected Corresponding Fellow of the American Psychiatric Association, in recognition of meritorious contributions to psychiatry, and became an International Fellow in 2002. The US Government engaged him as a panel psychiatrist to vet visa applications, and he was also a member of the Anglo-American Medical Society.

A keen skier since the early 1960s, firstly in St Moritz and then regularly in Zermatt, he was a member of the Kandahar, Downhill Only and Ski Club of Great Britain. Indeed, he became something of a local hero in Zermatt when, in 1964, his swift action in accessing vaccine during a typhoid epidemic saved the town from disaster. He introduced many friends, entertainers and patients to the mountains, and was skiing elegantly even last February, although no longer able to repeat his ascent of the Mont Rosa on skins!

He died of complications following cardiac surgery in Brighton on 12 June 2002, aged 80. His marriage to Clarissa Merton ended in divorce in 1963.

Thereafter, he lived happily with his partner, Penny Buckland, who survives him. There are no children.

Penelope Buckland

\title{
reviews
}

\section{Safety in Psychiatry: The Mind's Eye}

By The Royal College of Psychiatrists. London: Gaskell (Video and support materials). 2000. $f 88.13$.

ISBN: 1-901242-56-0

The Royal College of Psychiatrists has rightly been in the vanguard of promoting safety and security for its trainees. This training pack aims to introduce psychiatric trainees and other health care professionals to the vital elements of safe working practices, and does so with the aid of a set of teaching materials that are first rate in their content and highly professional in their production. The materials consist of a 16-page information booklet for the use of trainees, a 22-minute videotape and accompanying tutor notes to facilitate group learning. Although the materials could be viewed in isolation, their structure is such that they lend themselves best to being used as part of a group teaching exercise, and it is through this that trainees will undoubtedly get the most from the pack.

The information booklet is comprehensive. The video is excellent and benefits from narration by Anthony Clare, communicator par excellence. The tutor notes provide a thoughtful framework for incorporating the materials into a teaching seminar lasting 60-90 minutes. This would be invaluable for anyone wishing to provide structured induction training in personal safety awareness and security measures. Psychiatric tutors wishing to do the job themselves could do much worse than adopt this training pack in their induction arrangements. Combined with appropriate training in breakaway techniques, it would provide the key elements of a safety training programme. Inevitably, such materials cannot cover all conceivable situations or convey all that might be needed by way of knowledge of risk assessment. When used in group

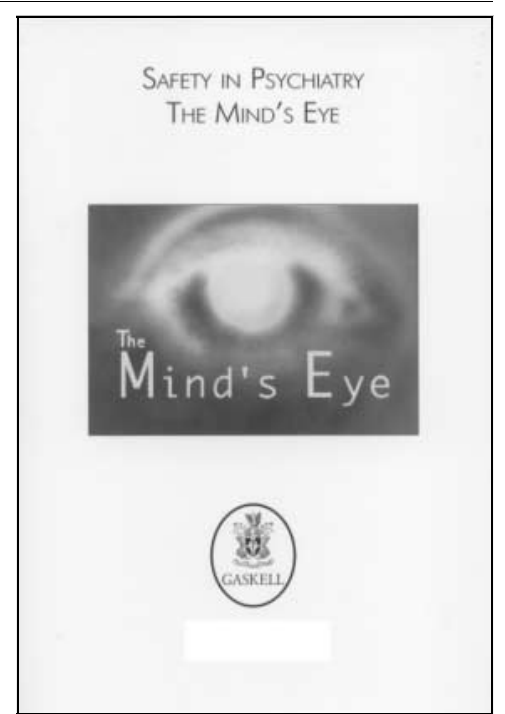

teaching, however, and repeated at appropriate intervals, trainees (and perhaps their senior colleagues) would learn much of value from the pack. If 
there is one minor quibble, it is that the focus is heavily on psychiatric trainees. Safety concerns all health professionals, of course, and the fundamental principles espoused in this pack could apply to many others in the NHS. One wonders if the College has the energy to re-work the material for a wider audience. If so, it could be a real money-spinner.

This minor point aside, Safety in Psychiatry reflects great credit on the College and those involved in its production. For anyone carrying responsibility for the safety of trainees, there can be only one message: buy, buy, buy!

David Newby Consultant Psychiatrist, Leeds Community \& Mental HealthTeaching Trust

\section{Maudsley Discussion Paper 11. Should Mental Health Nurses Prescribe?}

By K. Gournay and R. Gray. London: Institute of Psychiatry. 21 pp. 2001. $f 4.00$ (pb).

ISBN: 0-9500289-4

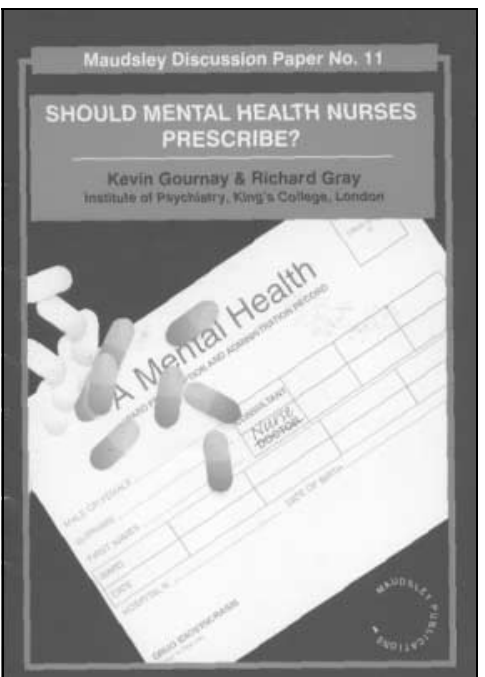

This paper explores the context of mental health nurse prescribing and covers such considerations as rationale, supervision, training and evaluation. Although well researched and systematically argued, its perspective is medically orientated and this narrows the scope of the discussion.

The rationale is rightly argued from the basis of patient need; but it is from a public health and resource viewpoint, rather than the more compelling one of continuity of care. As in other areas of chronic disease management, the continuing contact of the nurse with the patient informs the process of prescription review and adjustment. Nurse involvement could alter the focus from treating patients pharmaceutically, to putting medication in the context of a care plan, which balances symptom control against side-effects.

A somewhat sweeping assumption is made against nurse prescribing through citing the 'anti-medical' model adopted by some mental health nurses, thereby assuming they would be reluctant to prescribe. As for the medical profession, nursing has a code of practice that is subject to professional and legal accountability. Therefore, it is slightly presumptuous to consider that nurses would fail in their duty of care in prescribing to any greater degree than psychiatrists. The same principles apply to the rather convoluted discussions around which nurses should prescribe which drugs.

The paper only considers the role of community mental health nurses, ignoring the fact that this group comprises only $12 \%$ of qualified mental health nurses. The more urgent need for nurses to be able to initiate, titrate and alter medication often lies in the hospital or group home environment. It would be useful to consider these issues in relation to independent and/or supplementary prescribing, and the need for good collaborative working and robust shared-care arrangements.

The discussion around evaluation of the effectiveness of nurse prescribing suggests using randomised controlled trials. Although this method is often considered the gold standard of research, it may not evaluate adequately the finer points of prescribing practice or user satisfaction. Given the evidence base quoted in the paper on current prescribing efficacy by psychiatrists, it might be timely to consider robust evaluation of all prescribing for mental health patients, using both quantitative and qualitative methods.

In conclusion, much of this paper has been superseded by recent events and this is its main weakness. The Government is moving fast on nurse prescribing. If this paper is to have any real impact on the current debate, it needs to link more directly with the mainstream to avoid being dragged along on the coat-tails of directives from the Department of Health.

F. Winstanley Senior Lecturer in Community Nursing and Nurse Prescribing ， R. Dibblee Community Mental Health Nurse, Suffolk College, School of Health and Applied Sciences, The Ipswich Hospital NHS Trust, Heath Road, Ipswich IP4 5PD

\section{EBB Evidence-Base Briefing: Dementia. A Compilation of Secondary Research Evidence, Guidelines and Consensus Statements}

By Claire Palmer. London: Gaskell. 1999. 96 pp. $f 15.00$ (pb).

ISBN: 1-901242-35-8

Pursuing best practice in our brave new world of evidence-based medicine demands considerable personal effort to find out 'what is known'. As an old age psychiatrist, and regular searcher of the

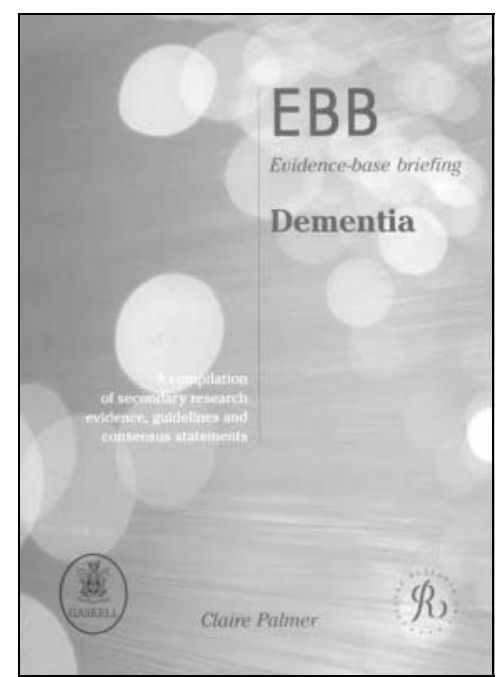

literature online, I was intrigued by the notion of a book that compiles the evidence-base for dementia. Searching online for evidence from my desk at work, the answer has always been 'too much' to get hold of and at the same time 'too little' that is relevant to my own practice. The central concept of this book is that the author, working within the College Research Unit, searches for evidence (of vastly differing qualities) and lays it out in a way that enables scrutiny. The book sets out its search methodology clearly, cites its sources and then presents 'the evidence' with references and an attempt to weigh its importance. The book's remit is to compile secondary research evidence, not primary studies and papers Therefore, it is a rather sad reflection on the paucity of the evidence, that so much of it is the national guidelines of the College or the American Psychiatric Association, or evidence-based guidelines relying on studies of moderate quality or poorer, rather than systematic reviews and critically appraised research summaries. This is not the fault of the author, who has done a creditable job to pull these dry guidelines together. But the larger point is that the College and its publishing arm, Gaskell, have missed an opportunity with this type of static publication. The same material together with the hugely useful website links and critical appraisal resources should be accessible on the College website or on CD-ROM, even at a cost. Searching would be easier, links to other resources would be enhanced and the search could be as contemporary as the day you access the site (not as old as September 1998). The shame is that, for all the author's hard work, the book is now way out of date. The idea of an evidence-based briefing is a good one because of the approach, but not in this format. Does the book help reduce the personal effort required to get on top of the evidence? Not really.

Stephen Burton Consultant and Senior Lecturer in Old Age Psychiatry, Ladywell Unit, University Hospital Lewisham SE13 5QY 